\title{
Early-onset Male Androgenetic Alopecia and Metabolic Syndrome: Are They Associated?
}

\author{
${ }^{1}$ Sampada A Thakare, ${ }^{2}$ Adarshlata Singh
}

\begin{abstract}
Aims and objectives: To study the pattern of early-onset male androgenetic alopecia (AGA) and its association with metabolic syndrome (MetS).
\end{abstract}

Study design: A case-control study was conducted in the tertiary care center, Department of Dermatology, from year 2012 to 2014.

Materials and methods: A total number of 100 patients, 50 male patients with early-onset AGA cases and 50 age-matched controls, were enrolled. The Norwood-Hamilton classification was used to assess the grade of AGA. Metabolic syndrome was defined according to the National Cholesterol Education Program Adult Treatment Panel III criteria. Blood pressure, blood glucose, and lipid parameters along with waist circumference were assessed in all the study participants. Statistical analysis was done by using descriptive and inferential statistics using chi-square test and $Z$ test for difference between two means. The statistical software used in the analysis was Statistical Package for the Social Sciences 17.0 and Graph Pad Prism 5.0 , and the results with $(p<0.05)$ were considered significant.

Results: Most common grades of early-onset male AGA were $38 \%$ with grade IV, $26 \%$ with grade IIIv (vertex), and $16 \%$ with grade III. $50 \%$ of the case group with early-onset male AGA and $10 \%$ of control group patients had MetS $(p<0.05)$. As compared with controls, patients with early-onset AGA had a statistically significant mean value for fasting blood sugar level ( $p$-value 0.001 ), triglyceride level ( $p$-value 0.013 ), waist circumference ( $p$-value 0.004$)$, systolic blood pressure ( $p$-value 0.006 ), and diastolic blood pressure ( $p$-value 0.010 ) respectively. There was no significant association between early-onset male AGA and serum levels of HDL, LDL, VLDL, and cholesterol ( $p>0.05)$.

Conclusion: It is inferred from this study that the most common grade of early-onset male AGA was grades IV and III vertex. There also was association of early-onset male AGA with MetS. More prospective studies are required with a large sample size to justify the association between early-onset male AGA and MetS.

Keywords: Androgenetic alopecia, Male, Metabolic syndrome.

How to cite this article: Thakare SA, Singh A. Early-onset Male Androgenetic Alopecia and Metabolic Syndrome: Are They Associated?. Int J Recent Surg Med Sci 2016;2(1):5-9.

\footnotetext{
${ }^{1}$ Senior Resident, ${ }^{2}$ Professor and Head

1,2Department of Dermatology, Venereology and Leprosy Jawaharlal Nehru Medical College, Wardha, Maharashtra, India

Corresponding Author: Sampada A Thakare, Senior Resident Department of Dermatology, Venereology and Leprosy Jawaharlal Nehru Medical College Wardha, Maharashtra India, Phone: +918605599449, e-mail: sampada.thakare@ yahoo.com
}

\section{Source of support: Nil}

Conflict of interest: None

\section{INTRODUCTION}

Hair is an important part of self-expression as it is a symbol of attitude, culture, and religion. Alopecia induced by androgens in genetically predisposed individuals is termed as androgenetic alopecia (AGA). ${ }^{1}$ The onset of male androgenetic alopecia before 35 years of age is considered as early-onset AGA. ${ }^{2}$ Androgenetic alopecia is caused by greater peripheral sensitivity to androgens. The free testosterone is converted into dihydrotestosterone (DHT) by 5alpha-reductase, and this leads to follicular miniaturization. ${ }^{1}$ Similarly, 5alpha-reductase has been detected in blood vessels and the heart, as they have DHT receptors, which are involved in smooth muscle proliferation in blood vessels, a key phenomenon in arteriosclerosis, together with lipid deposition. Consistent with this possibility, Klemp et $\mathrm{al}^{3}$ reported that reduced blood flow in the scalp could be associated with early-onset AGA. Metabolic syndrome (MetS) is a clustering of risk factors, which are of metabolic origin and are accompanied by increased risk of cardiovascular disease and type-2 diabetes mellitus. Recently, studies have shown associations between early-onset AGA and MetS. Thus, an understanding of the relationship between early-onset male AGA and MetS may be helpful in preventing severe systemic diseases.

\section{MATERIALS AND METHODS}

This study was conducted in the tertiary care centre, Department of Dermatology, Venereology and Leprosy, from year 2012 to 2014. A written informed consent was taken from all the cases and controls of the study. An ethical clearance was given by the committee.

Inclusion criterion for the total number of 100 patients ( 50 cases and 50 controls) between the age of 18 to 35 years were included. Also, inclusion criteria for cases included patients with early-onset AGA (with grade $\geq 3$ AGA according to Norwood-Hamilton ${ }^{4,5}$ grading), and 50 agematched controls without AGA were included. Exclusion criteria for both cases and controls were known cases of diabetes mellitus, hypertension, congenital adrenal hyperplasia, familial genetic syndrome, i.e., familial 
Table 1: Distribution of patients according to grade with early-onset AGA in the case group

\begin{tabular}{|c|c|c|c|c|c|c|c|c|c|c|}
\hline \multirow[b]{2}{*}{ Age Group (yrs) } & \multicolumn{10}{|c|}{ Grade of Androgenetic alopecia } \\
\hline & Grade III & Grade IIIV & Grade IIIa & Grade IV & Grade IVa & Grade V & Grade Va & Grade VI & Grade VII & Total \\
\hline $18-23$ & $8(16 \%)$ & $5(10 \%)$ & $0(0 \%)$ & $9(18 \%)$ & $0(0 \%)$ & $1(2 \%)$ & $0(0 \%)$ & $0(0 \%)$ & $0(0 \%)$ & $23(46 \%)$ \\
\hline $24-29$ & $0(0 \%)$ & $8(16 \%)$ & $0(0 \%)$ & $8(16 \%)$ & $1(2 \%)$ & $4(8 \%)$ & $0(0 \%)$ & $0(0 \%)$ & $0(0 \%)$ & $21(42 \%)$ \\
\hline $30-35$ & $0(0 \%)$ & $0(0 \%)$ & $0(0 \%)$ & $2(4 \%)$ & $0(0 \%)$ & $1(2 \%)$ & $0(0 \%)$ & $1(2 \%)$ & $2(4 \%)$ & $6(12 \%)$ \\
\hline Total & $8(16 \%)$ & $13(26 \%)$ & $0(0 \%)$ & $19(38 \%)$ & $1(2 \%)$ & $6(12 \%)$ & $0(0 \%)$ & $1(2 \%)$ & $2(4 \%)$ & $50(50 \%)$ \\
\hline
\end{tabular}

hypertriglyceridemia, thyroid disease, Cushing's disease, nephrotic syndrome, who were receiving androgen, antiandrogens, slimming or insulin-sensitizing drugs, or insulin treatment; had used glucocorticoid agents during the previous 6 months; and were experiencing changes related to their bodies.

Detailed history of the patient regarding duration of hair fall, smoking, alcohol intake, and family history of AGA was recorded.

Waist circumference was measured at the midpoint between the lower margin of the last palpable rib and the top of the iliac crest, using a stretch-resistant tape that provides a constant $100 \mathrm{~g}$ tension. The resting blood pressure was recorded in the right arm in the supine position by a mercury sphygmomanometer with the standard size cuff, after a resting period of 3 minutes. A second reading was taken after 10 minutes, and the mean of the two readings was considered.

The samples for the fasting blood sugar and lipid profile were taken early in the morning after a fasting period of 10 to 12 hours. Lipid profile (total cholesterol, HDL, triglycerides) was estimated by using the GOD-POD method by Randox kit. LDL was calculated using Friedewald formula. ${ }^{6}$

The Norwood-Hamilton classification was used to assess the grade of AGA., ${ }^{4,5}$ Metabolic syndrome was defined according to the National Cholesterol Education Program (NCEP) Adult Treatment Panel III (ATP III) criteria. $^{7,8}$

- Waist circumference $\geq 102 \mathrm{~cm}$ in males,

- Triglyceride value $\geq 150 \mathrm{mg} / \mathrm{dL}$,

- HDL-C $<40 \mathrm{mg} / \mathrm{dL}$ in males,

- $\mathrm{FBS} \geq 110 \mathrm{mg} / \mathrm{dL}$

- $\mathrm{BP} \geq 130 / 85 \mathrm{~mm} \mathrm{Hg}$.

The data were analyzed by statistical analysis using descriptive and inferential statistics chi-square test and $\mathrm{Z}$ test for difference between two means.

The statistical software used in the analysis was Statistical Package for the Social Sciences 17.0 and Graph Pad Prism 5.0 and the results with $(\mathrm{p}<0.05)$ were considered significant.

\section{RESULTS}

A total number of 100 patients, 50 male patients with early-onset AGA cases and 50 age-matched controls,
Table 2: Presence of MetS in patients of case and control groups

\begin{tabular}{lllll}
\hline Metabolic & & Control & & \\
syndrome & Case group & group & $\chi^{2}$-value & p-value \\
\hline Present & $25(50 \%)$ & $5(10 \%)$ & 19.04 & $<0.0001 \mathrm{~S}$ \\
Absent & $25(50 \%)$ & $45(90 \%)$ & & \\
\hline Total & $50(100 \%)$ & $50(100 \%)$ & & \\
\hline
\end{tabular}

S: Significant

were studied. The mean age in the case group with earlyonset AGA was $24.04 \pm 4.06$ and the control group was $23.94 \pm 4.69 .66 \%$ patients of the case and $40 \%$ patients of the control group had statistically significant positive history of smoking $(\mathrm{p}<0.05)$. A total $64 \%$ of patients in the case group and $34 \%$ in the control group had significant positive family history for AGA $(\mathrm{p}<0.05)$. As shown in Table 1, most common grades of early-onset male AGA was $38 \%$ with grade IV, $26 \%$ with grade III (vertex), and $16 \%$ with grade III. In the age group 18 to 23 years, the most common grades of early-onset male AGA were grade IV (18\%) and grade III (16\%); in the age group of 24 to 29 years, grade IV (16\%) and IIIv (16\%); and in the 30 to 35 years' age group, grade IV (4\%) and VII (4\%). There was positive association between the severity of AGA grade and increasing age. In Table 2, 25 (50\%) patients with early-onset male AGA of the case group and $5(10 \%)$ patients of the control group had MetS, whereas MetS was absent in $25(50 \%)$ patients in the case group and $45(90 \%)$ patients in the control group. This difference was significant $(\mathrm{p}<0.05)$.

According to Table 3, the mean levels of FBS were $106 \pm 26.76$ in the case group and $92.42 \pm 10.38$ in the control group and the difference between means was statistically significant $(\mathrm{p}=0.001)$. The mean levels for triglyceride were $135.06 \pm 37.11$ in the case group and $118.06 \pm 29.96$ in the control group and the difference between means was statistically significant $(p=0.013)$. The mean value for waist circumference was $95.68 \pm 9.82$ in the case group and $90.01 \pm 9.03$ in the control group and the difference between means was statistically significant $(\mathrm{p}=0.004)$. The mean value for SBP was $125.64 \pm 9.40$ in the case group and $121.12 \pm 6.39$ in the control group and the difference between means was statistically significant $(p=0.006)$. The mean value for DBP was $83.72 \pm 4.44$ in the case group and $81.48 \pm 4.03$ in the control group and the difference 
Early-onset Male Androgenetic Alopecia and Metabolic Syndrome: Are They Associated?

Table 3: Components of MetS according to ATP III criteria in case and control groups

\begin{tabular}{|c|c|c|c|c|c|}
\hline & Group & $N$ & Mean & Std. deviation & $p$-value \\
\hline \multirow[t]{2}{*}{ FBS (mg/dL) } & Case & 50 & 106.00 & 26.76 & $0.001 \mathrm{~S}, \mathrm{p}<0.05$ \\
\hline & Control & 50 & 92.42 & 10.38 & \\
\hline \multirow[t]{2}{*}{$\mathrm{HDL}(\mathrm{mg} / \mathrm{dL})$} & Case & 50 & 37.16 & 5.91 & $0.113 \mathrm{NS}, \mathrm{p}>0.05$ \\
\hline & Control & 50 & 38.78 & 4.02 & \\
\hline \multirow[t]{2}{*}{ Triglycerides (mg/dL) } & Case & 50 & 135.06 & 37.11 & $0.013 \mathrm{~S}, \mathrm{p}<0.05$ \\
\hline & Control & 50 & 118.06 & 29.96 & \\
\hline \multirow[t]{2}{*}{ Waist circumference $(102 \mathrm{~cm})$} & Case & 50 & 95.68 & 9.82 & $0.004 \mathrm{~S}, \mathrm{p}<0.05$ \\
\hline & Control & 50 & 90.1 & 9.03 & \\
\hline \multirow[t]{2}{*}{ Systolic blood pressure $(\mathrm{mm} / \mathrm{Hg})$} & Case & 50 & 125.64 & 9.40 & $0.006 \mathrm{~S}, \mathrm{p}<0.05$ \\
\hline & Control & 50 & 121.12 & 6.39 & \\
\hline \multirow[t]{2}{*}{ Diastolic blood pressure $(\mathrm{mm} / \mathrm{Hg})$} & Case & 50 & 83.72 & 4.44 & $0.010 \mathrm{~S}, \mathrm{p}<0.05$ \\
\hline & Control & 50 & 81.48 & 4.03 & \\
\hline
\end{tabular}

S: Significant; NS: Nonsignificant

between means was statistically significant $(p=0.010)$. The mean value for HDL-C was $37.16 \pm 5.91$ in the case group and $38.78 \pm 4.02$ in the control group and the difference between means was statistically non-significant $(p=0.113)$.

There was no significant association between earlyonset male AGA and serum levels of LDL, VLDL, and cholesterol ( $p>0.05)$.

\section{DISCUSSION}

According to this study, results explain that there is less severe grade of AGA in Indian male population than in other Asian populations. Asian men with AGA have different characteristics from those of men of European descent. Thus, variations in grade of AGA might be due to different race and ethnicity. There was significant association between the early onset of AGA with MetS, family history, and smoking. This finding was supported by $\mathrm{Su}$ and $\mathrm{Chen}^{9}$ and Mosley \& $\mathrm{Gibbs}^{10}$, who observed positive association between smoking and AGA. The mechanisms by which smoking causes hair loss may be multifactorial. Smoking is deleterious to the microvasculature of the dermal hair papilla and smoke genotoxicants may damage the DNA of the hair follicle, which leads to an imbalance in the follicular protease or antiprotease system. Smoking-induced oxidative stress may lead to the release of proinflammatory cytokines that in turn results in follicular microinflammation and fibrosis. Smoking may yield a relative hypoestrogenic state by inducing increased hydroxylation of estradiol and inhibition of aromatase, which may contribute to an increase in androgen-dependent hair thinning.

Family history plays an important role in the development of alopecia, just as it does in cardiovascular disease. It was explained that the frequency of AGA in fathers of men with AGA is higher than in fathers of men without AGA. Androgen receptor gene, which is X-linked recessive, has been mentioned to be the cardinal prerequisite for balding, but other genes are also involved. Genetic sensitivity of hair follicles to DHT causes them to shrink when exposed to it. Hair growth inhibitory factor - beta, released from androgen-stimulated fibroblasts of the follicular dermal papilla - may cause hair growth inhibition, hair follicle miniaturization, and short lifespan, thereby preventing normal hair production. It has been reported that 5alpha-reductase exists in the blood vessels and the heart. ${ }^{11}$

Several previous studies have investigated the association between factors related to MetS and AGA. However, the results showed much controversy. An association between early-onset AGA and serious cardiovascular incidents, such as, myocardial infarcts and fatal ischemic heart disease, has been documented; however, the underlying mechanism of this association is still not understood. Patients with AGA undergo an abdominal redistribution of fat, which is considered an important cardiovascular risk factor and a key element for MetS. According to Arias-Santiago et al, ${ }^{12}$ people who meet ATP-III criteria are 2.59 to 3.5 times more likely to have a cardiovascular event during the next 10 years. Furthermore, the authors of those studies state that the ATP-III criteria correlate better with cardiovascular disease than other criteria used to define the MetS. Abdominal fat tissue is associated with serious metabolic disorders, such as, insulin resistance, hypertension, increased triglycerides, glucose intolerance, and diabetes mellitus. High serum androgen levels in AGA cases contribute to the proliferation of smooth muscle cells in vessels and increase the tendency to hypertension. Genetic sensitivity of hair follicles to DHT causes them to shrink when exposed to it. 5alpha-reductase is responsible for converting free testosterone (a major circulating androgen in men) into DHT. Hair growth inhibitory factor-beta, released from androgen-stimulated broblasts of the follicular dermal papilla - may cause hair growth 


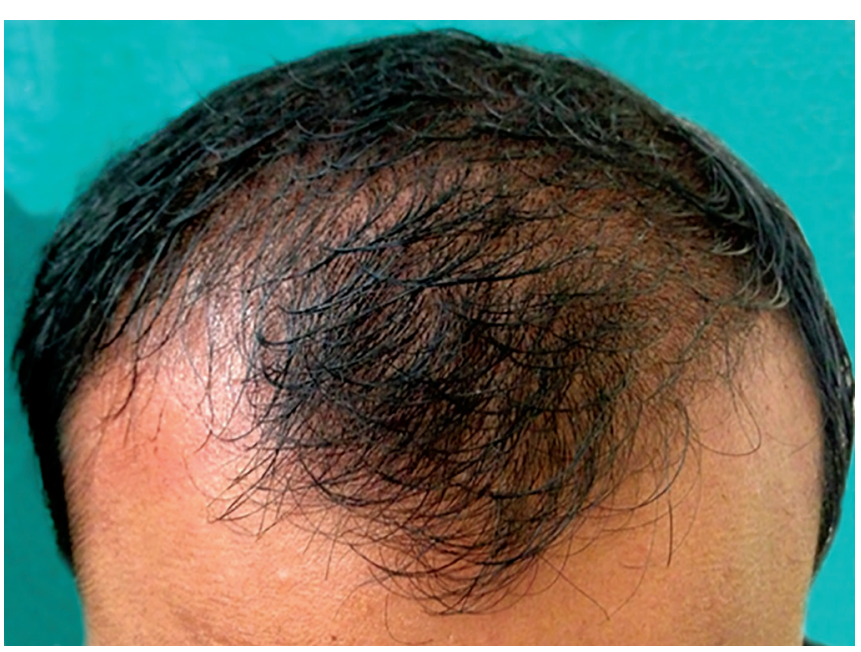

Fig. 1: Grade IIlv (vertex) AGA

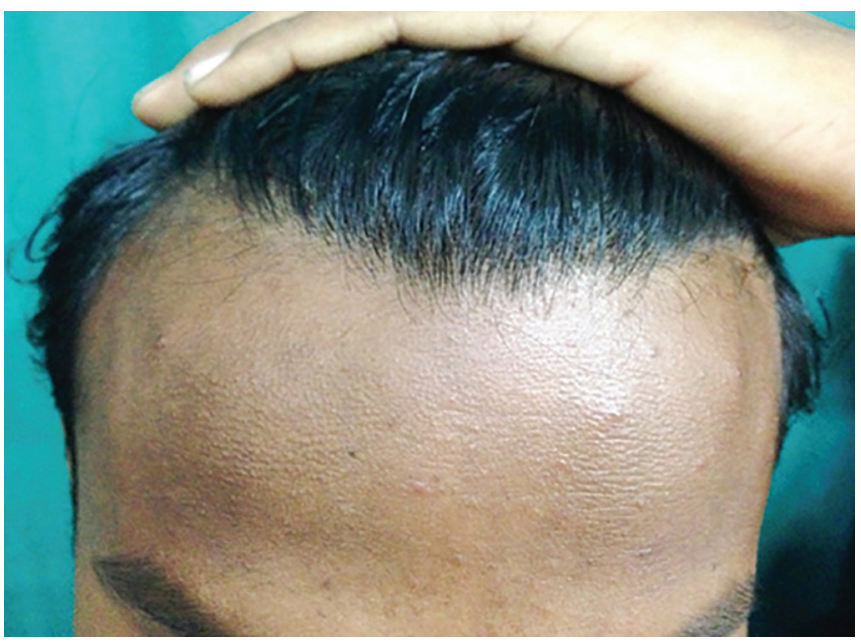

Fig. 3: Grade III AGA

inhibition, hair follicle miniaturization, and short lifespan, thereby preventing normal hair production. ${ }^{13}$

In this study, the most common grades of AGA were grades III and IV with presence of MetS 20 and 48\% respectively (Figs 1 and 2). According to Lesko et al, ${ }^{14}$ men with severe vertex baldness, hypertension, and high cholesterol levels had an even higher risk of MI before age of 60 years. This was supported by Paik et al, ${ }^{15}$ González-González et al, ${ }_{1}^{16}$ and Schnohr, ${ }_{17}$ who reported an increased risk of myocardial infarction accompanied by vertex baldness. The presence of androgen receptors in the arterial wall endothelium was shown to exist, but the direct effects of the androgens on vascular endothelium or functions remained unclear. Androgens were proved to decrease HDL-C levels in experimental studies. High values of TGs and low values of HDL-C were associated with the transition from atheroma to atherothrombosis. ${ }^{18}$ Therefore, investigation and control of lipid profiles in patients with AGA may be important to reduce this risk (Fig. 3). The inconsistency in the literature with the above study may be partially attributed to

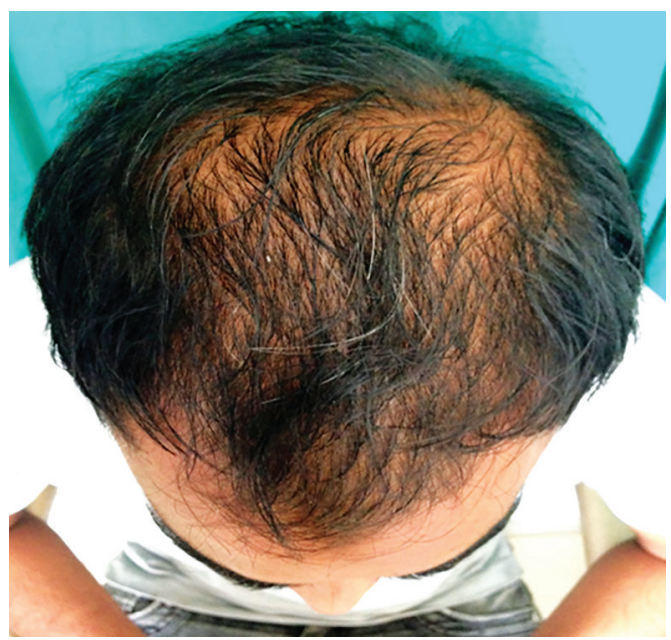

Fig. 2: Grade IV AGA

the different target populations studied and to the failure to control other confounding factors, such as, family history and smoking status. There may be a few variations in outcomes of this study with the other studies discussed above due to the following: (1) Different study design: Cross-sectional vs case control studies, (2) the definition of groups also varied in some studies, (3) Age: Early onset vs late onset baldness, and (4) different sample sizes.

The association between early-onset AGA and MetS can be explained by different mechanisms that are not exclusive but complementary. According to the above findings, screening for components of MetS by the dermatologist in patients with early-onset male AGA could prove useful for detection of at-risk individuals and for initiation of preventive therapy before cardiovascular disease develops.

\section{REFERENCES}

1. Sehgal VN, Kak R, Aggarwal A, Srivastava G, Rajput P. Male pattern androgenetic alopecia in an Indian context: a perspective study. J Eur Acad Dermatol Venereol 2007 Apr;21(4):473-479.

2. Acibucu F, Kayatas M, Candan F. The association of insulin resistance and metabolic syndrome in early androgenetic alopecia. Singapore Med J 2010 Dec;51(12):931-936.

3. Klemp P, Peters K, Hansted B. Subcutaneous blood flow in early male pattern baldness. J Invest Dermatol 1989 May;92(5):725-726.

4. Hamilton JB. Patterned loss of hair in man: types and incidence. Ann N Y Acad Sci 1951 Mar;53(3):708-728.

5. Norwood OT. Male pattern baldness: classification and incidence. South Med J 1975 Nov;68(11):1359-1365.

6. Friedewald WT, Levy RI, Fredrickson DS. Estimation of the concentration of low-density lipoprotein cholesterol in plasma, without use of the preparative ultracentrifuge. Clin Chem 1972 Jun;18(6):499-502.

7. Expert panel on detection, evaluation, and treatment of high blood cholesterol in adults. Executive summary of the 
third report of the National Cholesterol Education Program (NCEP) (Adult Treatment Panel III). JAMA 2001;285(19): 2486-2497.

8. Grundy SM, Cleeman JI, Daniels SR, Donato KA, Eckel RH, Franklin BA, Gordon DJ, Krauss RM, Savage PJ, Smith SC Jr. Diagnosis and management of the metabolic syndrome: An American Heart Association/National Heart, Lung, and Blood Institute scientific statement. Circulation 2005 Oct;112(17):2735-2752.

9. Su LH, Chen TH. Association of androgenetic alopecia with smoking and its prevalence among Asian men: a community based survey. Arch Dermatol 2007 Nov;143(11):1401-1406.

10. Mosley JG, Gibbs AC. Premature grey hair and hair loss among smokers: a new opportunity for health education? BMJ 1996 Dec 21-28;313(7072):1616.

11. Ellis JA, Stebbing M, Harrap SB. Genetic analysis of male pattern baldness and the 5-reductase genes. J Invest Dermatol 1998 Jun;110(6):849-853.

12. Arias-Santiago S, Gutiérrez-Salmerón MT, CastelloteCaballero L, Buendía-Eisman A, Naranjo-Sintes R. Male androgenetic alopecia and cardiovascular risk factors: a case-control study. Actas Dermosifiliogr 2010 Apr;101(3):248-256.
13. Sharma L, Dubey A, Gupta PR, Agrawal A. Androgenetic alopecia and risk of coronary artery disease. Ind Dermatol Online J 2013 Oct;4(4):283-287.

14. Lesko SM, Rosenberg L, Shapiro S. A case-control study of baldness in relation to myocardial infarction in men. JAMA 1993 Feb 24; 269(8):998-1003.

15. Paik JH, Yoon JB, Sim WY, Kim BS, Kim NI. The prevalence and types of androgenetic alopecia in Korean men and women. Br J Dermatol 2001 Jul;145(1):95-99.

16. González-González JG, Mancillas-Adame LG, FernándezReyes M, Gómez-Flores M, Lavalle-González FJ, OcampoCandiani J, Villarreal-Pérez JZ. Androgenetic alopecia and insulin resistance in young men. Clin Endocrinol. 2009 Oct 1;71(4):494-499.

17. Schnohr P. Longevity and Gray hair, baldness, facial wrinkles, and arcussenilis in 13,000 men and women: The copenhagen city heart study. J Gerontol A Bio Sci Med Sci 1998 Sep;53(5):M347.

18. Sasmaz S, Senol M, Ozcan A, Dogan G, Tuncer C, Akyol O, Sener S. The risk of coronary heart disease in men with androgenetic alopecia. J Eur Acad Dermatol Venereol 1999 Mar;12(2):123-125. 